\title{
Addressee as a key factor of courtroom discourse production
}

\author{
Olga Krapivkina $^{1 *}$, Kseniya Kolesnikova ${ }^{2}$, Irina Borisovskaya $^{3}$ and Elena Taranova ${ }^{3}$ \\ ${ }^{1}$ Irkutsk National Research Technical University, 664074 Irkutsk, Russia \\ ${ }^{2}$ Belgorod Law Institute of Ministry of the Internal of the Russian Federation named after I.D. Putilin, 308024 Belgorod, Russia \\ ${ }^{3}$ Belgorod National Research University, 308000 Belgorod, Russia
}

\begin{abstract}
The article analyses the role of the addressee as a factor determining discourses of legal professionals. The important role of this factor makes it necessary to account for the effect of the addressee on discourse production, identify linguistic and cognitive mechanisms optimizing communicative interaction of the addresser and the addressee in the courtroom. The focus on the addressee, addressee's phenomenological experience and knowledge makes legal discursive practices dialogical, and intensifies their interactive characteristics. Special attention is paid to the linguistic cognitive mechanism "transition from the term to the notion" which allows for formation of the shared interpretation context when professionals interact with lay persons in the courtroom setting. Clarity of judicial speeches depends on the ability of the speaker to switch from the professional code to the language of lay people, define legal terms through lay concepts. The novelty of the research is due to the choice of the research trajectory which is based on the issue of the addressee for producing courtroom discourses. The article concludes that the perlocutionary effect of the communication depends on the ability of the speaker to accommodate to lay participants, to the knowledge and expectations of the lay audience
\end{abstract}

\section{Introduction}

According to Pascal, when trying to persuade someone, one should always see the one who this person persuades, know one's mind and heart, rules by which one is guided, and the objects that one loves [1].

Aristotle emphasized a special role of the addressee arguing that "speech consists of three elements: the speaker, the subject, and the addressee who is the ultimate goal of everything" [2].

In ancient rhetoric, the addressee was an active, "interpretive" recipient. Rhetoric aims to find persuasion means rather than to persuade. Diversity of persuasion means depends on the complexity of the audience.

The theory of speech acts (J. Austin, J. R. Searle, G. P. Grice, and others), sociolinguistics (R. T. Bell, V. I. Karasika, I. P. Tarasova), cognitive linguistics (T. A. van Dijck, V. Z. Demyankov, V. Kinch, E. S. Kubryakova, et al.), and the theory of argumentation (H. Perelman, F. van Yeemeren, R. Grootendorst, et al.) contributed to the issue of the addressee factor.

The idea to take into account the addressee was emphasized by Chafe. He said about the need to study "intellectual and operational capabilities of the addressee within a specific speech context: the speaker "packs" the discourse content in an efficient way so that the addressee can easily assimilate it" [3].

The issue of the addressee as a key factor of discourse production was developed by the representatives of linguistic pragmatics. Stolnayker says that "in order to achieve mutual understanding, it is extremely important that participants have a common set of presuppositions" [4].

Clark and Carlson identified two types of recipients (addressees and casual listeners) depending on their role in the speech act and informing power of the utterance. The researchers argued that "when the speakers construct their utterances, they assign different roles to different listeners, and plan their utterances based on their knowledge, beliefs and assumptions about what they know and what they listen to according to their roles" [5].

The concept "addressee" or "audience" is one of the key elements in the Perelman's model of argumentation: "each discourse is addressed to an audience ... Since discourse is interpreted by the audience, the physical absence of readers can make the writer think that she is alone in the world, although her text is always consciously or unconsciously determined by the audience. The speaker really has to accommodate to his audience if she wants to achieve some effect. The same discourse has different effects on the incompetent audience and the philosopher" [6].

The article 'The addressee's factor' (1981) by Arutyunova became a program for the Russian linguistics. The author deals with the influence of addressee's "roles or functions" on the addresser. She described the addressee factor in its relation to (1) speech acts, (2) internal speech and (3) literary texts. According to Arutyunova, we use the concept "addressee" while emphasizing the conscious orientation of speech utterances to a specific or non-specific person who can be characterized in a certain way. The

\footnotetext{
Corresponding author: koa1504@mail.ru
} 
communicative intention of the author should be consistent with addressee's features. In other words, every speech act is designed for a specific addressee" [7]. The researcher draws attention to the fact that in real discursive practices, there is "pressure" of the addressee on discourses.

Paying tribute to the above-mentioned theories, it should be noted that the issue of the addressee in legal communication is understudied. The important role of this factor requires research on linguistic cognitive mechanisms, optimizing interaction of the discourse producer and the recipient. "Consistency of communication parameters of the producer and the addressee is one of the important conditions for communication efficiency.

This article studies courtroom discourses which involve asymmetrical social situations, encounters between experts (judges and lawyers) and laymen (jury members, defendants and witnesses), i.e., interactants with different status and competences. Specifically, this article deals with various accommodative processes occurring between courtroom participants.

\section{Materials}

The research focuses on the key legal-lay trial genres: closing arguments, witness examinations and summingup. The material of the study was transcripts of closing arguments (76 units), witness examinations (83 units), and summing-up (67 units). To avoid deception through idiolect, we analyzed discourses of different speakers. The examination corpora include texts produced by 76 attorneys and 67 judges.

Despite the fact that the accuracy of court transcripts is extremely difficult to verify, the study of verbal aspects of courtroom discourse practices using these sources is widespread in linguistics (Aldridge, Cotterill; Heffer, Felton, etc.), since it excludes the presence of a researcher who may influence the communicative behavior of trial participants.

The author recognizes that it is not possible to investigate phonetic, prosodic or paralinguistic features. Transcripts are not reliable sources for studying nonverbal features, contractions, and pauses. There is a considerable degree of subjectivity in the transcriber's interpretation. However, linguistic features are preserved by the transcriber. There are no significant differences at lexical and syntactic levels between the utterances heard in court and those in the transcripts.

\section{Results and Discussion}

Given the heterogeneity of the addresser and the addressee, we will categorize them according to three criteria [7]: 1) communicative roles; 2) social roles; 3) relations between them.

In terms of the communicative role, the communicants of judicial discourse practices are an addresser and an addressee. The addressees can be both individual (the judge) and collective (the jury).
Social roles of courtroom participants are determined by the institutional context. There are two categories of participants: 1) representatives of the institute of justice (prosecutors, defense attorneys and judges), and 2) temporary participants (jury, witnesses, victims, defendants). The addressee is the jury members and the judge. Other participants can be considered as recipients, they are not the Other whom the speaking subject initiates to experience the interpretants introduced into the discourse. The speaker does not seek to exert a speech impact on them, since they do not assess conformity of the world she constructs to real world facts and common sense. For example, witnesses are only the tools used to involve the jury in the context constructed by the speaker. According to Evans, "a witness for a lawyer is a tool like a drill for a dentist, and testimony can be compared with tooth extraction - a painful process that is difficult to control" [8].

Interaction in jury trials is asymmetrical in terms of communicative dynamics and level of legal knowledge of the key participants [9]. The addresser and the addressee are y subjects with different cognitive baggage and social status which gives rise to a complex dialogic game based on subjective reconstruction of the phenomenological experience, on the one hand, and logical principles and legal rules, on the other one. Experts enter the courtroom with expert knowledge, while the jurors - with life experience and common sense. The ultimate goal of their interaction is creation of a shared context of interpretation, in other words, a discourse of concord.

Lawyers have been taught to follow 'paradigmatic' legal principles and procedures, and are well aware of the contribution; an evidential point might make to their logic-based legal case. At the same time, they are equally well aware of the need to communicate with and persuade a group of lay people (jury members) who are unlikely to reason in a paradigmatic fashion with respect to evidence detailing the crime narrative at the heart of the case [10].

Communicative asymmetry creates a discoursal tension which is manifested in both the macrolinguistic structures of courtroom genres and the microlinguistic choices of the lawyers.

Professional training contributes to mutual understanding between members of the same discourse community. However, lay participants will inevitably not have the same training and understanding.

Metaphorically, lawyers come into law before they come into court which affects the way they view courtroom proceedings. The lay participants, on the other hand, come into court without such a legal preparation. The professional members understand goal orientations and special constraints, while the lay participants will often not do so. While the overall goal of the trial is clear to the jury members, the entire thrust of the prosecution or defence argument is probably not be so.

The jury is holding a disadvantageous position derived from a lack of specific legal knowledge which is made verbally explicit during the trial. 
Asymmetry of knowledge predetermines dialectical coexistence of various forms of discursive interaction, transition from one form to another one: the lay people perceive expert knowledge only at the conceptual level. In order to integrate her world into lay consciousness, the expert is forced to ontologize her own interpretant in the possible world of the Other. As a result, the ontologized interpretant becomes shared knowledge.

This determines the hybrid nature of courtroom discourses.

Jurors are encouraged to use their common sense and knowledge of the world when deliberating on the 'facts' in the case.

That is why you are there. Twelve people coming from different backgrounds, different experiences, but bringing your joint experience of the world and your commonsense to bear upon the facts. So you are the ideal tribunal for dealing with questions of fact.

Jury members $\mathrm{J}$ come into court not as experts in law or expert triers of fact. Yet the grounds for their decisions are expertus, or known by experience, their experience of everyday life. Bruner reformulated it as a folk psychology - a sense of the world which is common to the community, 'a system by which people organize their experience in, knowledge about, and transactions with the social world' [11]. The 'organizing principle' of this folk psychology in most, if not all cultures is narrative in nature: "Folk psychology is about human agents doing things on the basis of their beliefs and desires, striving for goals, meeting obstacles which they best or which best them, all of this extended over time".

Thus, jury members bring common sense and lay experience rather than legal or scientific expertise into the courtroom. In other words, they use a narrative rather than a paradigmatic mode of thinking which should be taken into account by legal professionals.

The asymmetry of power is manifested in different ways at different stages of the trial. At the final stage, power belongs and is exercised by the jury members who resume communicative actions of the experts in a collective verdict. Throughout the previous stages, lawyers possess communication power while the jury members are deprived of the right to ask questions, express their viewpoints, etc. On the contrary, the legal professionals control information flows, decide what should be the focus of attention, what language tools should be used for making statements, what narration methods should be chosen. The communicative power of lawyers is due to 1) a higher status in the legal field, 2) possessing the legal communication code, 3) knowledge of the legal reality and circumstances of the case.

The jury members can formulate questions only in writing and submit them to the judge through the foreman. However, direct interaction with the participants is forbidden. If they ask a question directly, this will be a ground for the judgement reversal. These questions can identify "targets" for the manipulative influence on jury consciousness.

The intent of the courtroom speaker is to change the opinion of the jury about the crime event, construct a new world. The addressee factor makes discursive practices of legal professionals dialogical, intensifies their interactive characteristics.

The addresser tries to eliminate addressee's interactional discrimination, create a world where both communicants are equal. To this end, she uses strategies of speech dialogization, communicative adaptation to the addressee by switching to her language code.

One of these strategies is term-concept transition used to form a shared context of interpretation by communicating expert knowledge using signs of lay language. If the speaker does not want to be misunderstood, she is forced to bear in mind a naturally regulated communicative code that unites the communicants. Clarity of judicial speech is determined by the speaker's ability to take into account the addressee's factor and switch from the expert language to the lay communicative code, by verbalizing legal terms with concepts.

The following example is a fragment of the courtroom discourse. The defense attorney defines the criminal law terms "actual possession" and "constructive possession":

And you heard there was actual possession and constructive possession. You are in possession of the badge that's on you now. You have active control of that. These water bottles in front of you, you have constructive possession of them. You have control over them, but you do not have active control of them. It's not in your possession right now.

To achieve the perlocutionary effect and form discourse of concord, the lawyer explains the meaning of legal terms using analogy. Analogy is a common tool used by lawyers to explain abstract legal principles or elusive legal terms.

Explaining elusive legal terms by referring to the addressee's life experience is one of the most effective tools used in asymmetric communication. This forms an adequate interpretant of the described phenomenon. The attorney describes elusive legal terms actual possession and constructive possession using a simple icon image that can be easily visualized. In addition, the use of this tool allows the lawyer to be in a powerful position, construct a world where she is an expert, and her statements are believed to be true.

Thus, analogy is a powerful tool used to present legal terms that would otherwise appear alien to laymen.

As can be seen from the example, the attorney succeeds in offering a highly comprehensible explanation. The terms are epitomized in simple images that can be visualized, and phrasing may also result in an easily understood representation of the term.

Besides, figurative language helps keep the jury's attention. According to Bugliosi, "it is not difficult to keep juror's attention for one, two, or even three days if the lawyer can deliver a powerful, exciting summation that is sprinkled with example, metaphor and humor" [12].

Defense attorney: Dr. Bass, are you familiar with the criminal responsibility test relative to the M'Naghten Rule?

Expert: I certainly am.

Defense attorney: Would you explain this rule to the jury?

Expert: Of course. The M'Naghten Rule is the standard for criminal responsibility in Mississippi, as in 
fifteen other states. It goes back to England, in the year 1843, when a man by the name of Daniel M'Naghten attempted to assassinate the prime minister, Sir Robert Peel. He mistakenly shot and killed the prime minister's secretary, Edward Drummond. During his trial the evidence plainly showed M'Naghten was suffering from what we would call paranoid schizophrenia. The jury returned a verdict of not guilty, by reason of insanity. From this the M'Naghten Rule was established. It is still followed in England and sixteen states.

Defense attorney: What does the M'Naghten Rule mean?

Expert: The M'Naghten Rule is fairly simple. Every man is presumed to be sane, and to establish a defense on the ground of insanity, it must be clearly proven that when the defendant did what he did he was laboring under such a defect of reason, from a mental disease, that he did not know the nature and quality of the act he was doing, or if he did know what he was doing, he did not know it was wrong.

Defense attorney: Could you simplify that?

Expert: Yes. If a defendant cannot distinguish right from wrong, he is legally insane.

Defense attorney: Define insanity, please.

Expert: It has no significance, medically. It is strictly a legal standard for a person's mental state or condition [13].

Taking into account the specifics of the possible world of the addressee, the lawyer is trying to adapt expert knowledge to the cognitive baggage of the jury. The jury members do not know the M'Naghten Rule, by which insanity is determined. Therefore, the lawyer involves the addressee in discourse of concord (What does the M'Naghten Rule mean? Could you simplify that? Define insanity, please). The descriptions have simple structures and contain information that does not require expert knowledge for its interpretation.

The strategy is often used in the summing up. The judge constructs legal reality, turning abstract legal categories into lay concepts. Legal terms that form the expert community framework may be unfamiliar to the jury or have other meanings in the general English (murder, intent, negligence, bribe, aggravation, mitigation, burglary, assault, etc.). For example, burglary in the General English means breaking into a house, while in the legal English means breaking the law. The actions of a person who has entered the house with the intention of killing the owner (felony) will be qualified as burglary, which is at odds with the usual understanding [14]. The same word has different semantic descriptions that serve different purposes. Without breaking into autonomous subsystems, general language and legal language have qualitative differences.

One more strategy employed to simplify complex legal concepts and principles is metaphorization. According to Gotti, "metaphorization offers a series of advantages, such as terminological transparency, conciseness, and - the tangible quality of images from the physical world used to represent abstract and often complex concepts that would otherwise be difficult to define" [15].

Defense attorney: We're still looking. That smoking gun we 're trying to find. You might see the shadows of the outline of the gun, but they don't got the smoking gun. We're looking.

The use of the metaphor smoking gun is very common in closing arguments as a way to refer to the indisputable evidence. The defense attorney attempts to present the evidence as hard to prove his client's innocence.

Thus, even if it is impossible to avoid using legal concepts, experts can compensate for cognitive gaps.

Any verbal contact is an act of cooperation. All statements are produced and interpreted based on the knowledge of the context, topic and communication purposes. Mutual understanding is the result of joint efforts of communicants aimed at harmonizing individual points of view. In order to come into contact, the addresser must have a well-formed image of the addressee based on the information about her social and cognitive status, ideological and emotional attitudes, etc. What is accepted by one audience will not be accepted by another one. Therefore, the main goal of the speaker is to identify characteristics of the addressee in order to achieve a maximum perlocutionary effect.

Heterogeneity of the jury is one more problem as it causes certain difficulties for the speaker who has to take into account gender and age characteristics, moral and volitional qualities, values, individual experience, knowledge and cultural features of twelve individuals that make up the jury. Since the lawyers rely primarily on affective components, it is necessary to take into account differences in the emotional and psychological state of different categories of people.

However, attorneys have one advantage over other types of speakers: they can choose the addressee by challenging the jury. Trial lawyers are able to design their specific audience and then adapt their arguments and rhetoric to suit that audience [16].

\section{Conclusion}

Thus, in jury trials, legal professionals trained to think in a paradigmatic mode and use legal terminology are forced to accommodate to lay participants who think in a narrative fashion.

Complex legal issues and principles are used by the legal professionals. Successful communication with laymen depends on their ability to explain these issues in an accessible way. Informing about legal concepts and principles is important for preserving the expert credibility. The explanation of the law necessarily has to be accurate. At the same time, the law must be introduced in a simple and clear way [17].

Given that professionals and laymen have very different "input values" in terms of language, knowledge, status, and power, one might expect convergence because of a striving to decrease the gap between communicants and to increase efficiency in court procedures.

The addressee is an organizing center in courtroom communication, and selection of discursive tools is logically dependent on this factor. The perlocutionary effect is determined by the ability of the speaker to activate knowledge and ideas about the addressee creating her 
hypothetical image. The important role of the addressee for courtroom communication necessitates identification and study of linguo-cognitive tools that would optimize discursive interaction of the speaker and the addressee in the courtroom.

To be efficient communicants, legal professionals should be prepared for interaction with lay participants in the courtroom because the transition from legal to legal-lay interaction is a hard task. It is important to understand how jury members arrive at their verdicts, think in a narrative rather than in a paradigmatic mode.

\section{References}

1. B. Pascal, Logic and rhetoric (Minsk, TetraSystems, 1997).

2. Aristotle, Antique Rhetoric (Moscow, Moscow University Press, 1978).

3. W.L. Chafe, New in foreign linguistics, 11 (Moscow, Science, 1982).

4. R.S. Stolnaker, New in foreign linguistics: Linguistic pragmatics, 16 (Moscow, Progress, 1985).

5. G.G. Clark, T.B. Karlsson, New in foreign linguistics: Theory of speech acts, 17 (Moscow, Progress, 1986).
6. C. Perelman, The New Rhetoric. A Treatise on Argumentation (Notre Dame, University of Notre Dame Press, 1969).

7. N.D. Arutyunova, News of the AS USSR. Literature and language 40(4), 356 (1981).

8. O.A. Krapivkina, Tomsk State University Journal 423, 34 (2017).

9. O. Krapivkina, Journal of Language and Cultural Education 5(3), 77 (2017).

10. C. Heffer, The language of jury trial (Houndmills, UK, Palgrave, 2005).

11. J. Bruner, Critical Inquiry 18(1), 1 (1991).

12. V. Bugliosi, Outrage: The Five Reasons Why O.J. Simpson Got away with Murder (New York, Island Books, 1996).

13. J. Grisham, A Time to Kill (Penguin Random House, 2004).

14. Legal Dictionary. http:/legaldictionary.thefreedictionary.com

15. M. Gotti, Investigating Specialized Discourse (Bern, Peter Lang, 2008).

16. A. Bell, Language and Society 13, 145 (1984).

17. R. Aron, J. Fast, R. Klein, Trial Communication Skills (Deerfield, Ill., Clark Boardman Callaghan, 1996). 